\title{
Discovery of a crocodyliform tooth from the upper Eocene Ergilin Dzo Formation, Mongolia
}

\author{
Masaya Iijima, Takehisa Tsubamoto, Khishigjav Tsogtbaatar, Tsogtbaatar Chinzorig, and Soyol
}

Baasankhuu

Acta Palaeontologica Polonica 64 (4), 2019: 775-778 doi:https://doi.org/10.4202/app.00633.2019

\begin{abstract}
Although the distribution of Asian crocodyliforms was extended northwards during the Paleocene-Eocene greenhouse world, the fossil record in northern Asia becomes scarce towards the end of the Eocene. We here report the first crocodyliform (an isolated tooth) from the upper Eocene Ergilin Dzo Formation of southeastern Mongolia, the mammalian fauna of which defines the Ergilian Asian Land Mammal Age. The conical non-recurved crown, the near complete root with the central resorption facet, and its late Eocene age suggest the crocodyliform affinity of the tooth. The current finding represents one of the northernmost occurrences of crocodyliforms in the upper Eocene of Asia (paleolatitude ca. $49^{\circ} 30^{\prime}$ $\mathrm{N}$ ), and demonstrates that SE Mongolia probably met thermal requirements of crocodyliforms during the late Eocene.
\end{abstract}

Masaya Iijima [miijima8@gmail.com], School of Resources and Environmental Engineering, Hefei University of Technology, 193 Tunxi Road, Baohe, Hefei, Anhui 230009, China. Takehisa Tsubamoto [tsubamoto@sci.ehime-u.ac.jp ] (corresponding author), Graduate School of Science and Engineering, Ehime University, 2-5 Bunkyo-cho, Matsuyama, Ehime 790-8577, Japan. Khishigjav Tsogtbaatar [tsogtmondin@gmail.com], Tsogtbaatar Chinzorig [chinzorig.tsogtbaatar@gmail.com ], and Soyol Baasankhuu [baaska 970@gmail.com], Institute of Paleontology and Geology, Mongolian Academy of Sciences, P.O. Box 46/650, Chingeltei District-15160, Horoo-4, S. Danzan Street 3/1, Ulaanbaatar, Mongolia.

This is an open-access article distributed under the terms of the Creative Commons Attribution License (for details please see creativecommons.org), which permits unrestricted use, distribution, and reproduction in any medium, provided the original author and source are credited. 
Fofis Full text $(413.2 \mathrm{kB})$ 